\title{
Targeted Killing of Streptococcus mutans in Biofilms by a Pheromone Guided Antimicrobial Peptide HP30
}

\author{
Tian $\mathrm{XL}^{1}$, Chen $\mathrm{C}^{1}$, Cyr K ${ }^{1}$, Dong $\mathrm{G}^{1}$, Salim $\mathrm{H}^{2}$ and $\mathrm{Li} \mathrm{YH}^{* 1,2}$ \\ ${ }^{1}$ Department of Applied Oral Sciences, Dalhousie University, Halifax, NS, Canada \\ ${ }^{2}$ Department of Microbiology and Immunology, Dalhousie University, Halifax, NS, Canada
}

${ }^{*}$ Corresponding author: Li YH, Department of Microbiology and Immunology, 5981 University Ave. Rm5215 Halifax, Nova Scotia, Canada, B3H 1W2, Fax: 1-902-494-6621, Tel: 1-902-494-3063, E-mail: yunghua.li@dal.ca

Citation: Tian XL, Chen C, Cyr K, Dong G, Salim H, et al. (2017) Targeted Killing of Streptococcus mutans in Biofilms by A Pheromone-Guided Antimicrobial Peptide HP30. J Antibio Res 1(2): 201

Received Date: May 18, 2017 Accepted Date: June 12, 2017 Published Date: June 13, 2017

\begin{abstract}
Background: Streptococcus mutans is a leading cariogenic pathogen of dental caries worldwide. Clinically, eliminating S. mutans from dental biofilms using antibiotics is not practical, because these agents indiscriminately kill other members of the resident flora, leading to ecological disruption and other negative clinical consequences. To develop target-specific antimicrobials, we evaluated several fusion peptides and identified a new peptide HP30 that showed a high selectivity for targeted killing of S. mutans.

Methods: The selective killing activity of HP30 was evaluated against S. mutans and other related oral species in both mono- and dualspecies biofilm cultures.

Result: In the dual-species cultures, $80 \%$ of S. mutans cells were killed, but only $20 \%$ of S. sanguinis were killed following exposure to HP30 $(5.0 \mu \mathrm{M})$ for $15 \mathrm{~min}$. Similarly, $80 \%$ of $S$. mutans cells were killed but only $5 \%$ of Actinomyces naeuslundii were killed following the same exposure. The peptide-guided killing was also confirmed in the dual-species biofilms and the killing increased with increasing concentrations of HP30. However, a combination of low concentrations of HP30 with EDTA well maintained the killing activity against S. mutans in the biofilms. A S. mutans mutant lacking the ComD receptor only showed $20 \%$ of killing, while a ComD overexpression strain showed $90 \%$ of killing, suggesting that HP30 predominantly binds to the ComD receptor before triggering the selective killing. Conclusion: New peptide HP30 displays a high selectivity for targeted killing of $S$. mutans due to an improved binding of the peptide to the ComD receptor.
\end{abstract}

Keywords: Targeted killing; Pheromone-guided antimicrobial peptide; Quorum sensing, Biofilm; Streptococcus mutans

\section{Introduction}

Streptococcus mutans is a Gram-positive bacterium that lives in dental biofilms consisting of diverse species of microorganisms [1]. Under appropriate environmental conditions, $S$. mutans can rapidly produce acids from fermentable dietary carbohydrates and lower the biofilm $\mathrm{pH}$, initiating demineralization of the tooth surface or tooth decay [2]. S. mutans is therefore considered as a primary etiological agent of dental caries worldwide [3]. S. mutans can also be a cause of subacute infective endocarditis [4]. Although dental caries is not a life-threatening disease, diagnosing, treating and retreating caries and caries-related diseases is still a major financial burden to public health system. Clinically, eliminating $S$. mutans from dental biofilms using wide-spectrum antimicrobial agents is not practical, because these agents indiscriminately kill the resident microbes, leading to ecological disruption or other clinical negative consequences, such as allergy and development of antibiotic resistance [2,3]. Therefore, prevention of $S$. mutans and its associated diseases requires the development of new strategies that specifically target $S$. mutans without significant disruption of other resident members in dental biofilms.

In recent years, several attempts have been made to achieve target-specific antimicrobial therapy by coupling antibiotics to speciesspecific monoclonal antibodies or by creating fusion peptides that combine killing domains with bacterial recognition domains [5-8]. These narrow-spectrum antimicrobials can selectively target specific pathogens without significant effect on the other members of the resident microflora. Among these antimicrobials, pheromone-guided antimicrobial peptides (PG-AMPs) have been found to show the greater selectivity for targeted killing of bacteria. It is well known that quorum-sensing signal pheromones can specifically bind to the same bacterial species that produce them and function at nano-molar concentrations for coordinated 
activities $[9,10]$. The rationale of creating such antimicrobial peptides is based on the addition of a targeting domain of a quorumsensing signal pheromone from a target pathogen to the killing domain of a known antimicrobial peptide [11,12]. Both domains are fused via a short linker to generate a new hybrid peptide without detrimental change of their activities. Design of such peptides requires identification of two functionally independent molecules, a killing domain of a known AMP and a targeting domain of a species-specific, high-affinity binding molecule, such as quorum sensing signal pheromone $[11,12]$. The major advantage of such PG-AMPs is that the targeting domain can guide the fusion peptide to bind selectively to the target pathogen, leading to selective killing. Such pheromone-guided antimicrobial peptides have been successfully developed against various bacterial pathogens, including MRSA S. aureus, vancomycin- resistant E. faecalis, Pseudomonas spp and cariogenic pathogen S. mutans [6-8,11,12].

We previously constructed a peptide library and identified a salt-resistant peptide, IMB-2, which selectively killed $S$. mutans [12]. However, this peptide also showed a low level of non-specific killing in mixed cultures. To improve the selectivity, we screened and evaluated several more peptides and identified a new peptide HP30 that shows significant improvement in selective killing of S. mutans. We also explored the potential mechanism of such improved selectivity in the targeted killing by analyzing the ComD protein, the receptor of the quorum sensing signal pheromone of $S$. mutans. In addition, we found that a combination of a low concentration of HP30 with EDTA significantly enhanced selective killing of $S$. mutans cells in mixed biofilms. Here, we report the results of our evaluation of this peptide against $S$. mutans and other related oral species.

\section{Methods and Materials}

\section{Bacterial strains, media and growth conditions}

Bacterial strains used in this study were S. mutans UA159 (wt) and its derived strains, a comD deletion mutant $(\Delta$ comD), a ComD overexpression strain (ComD-Ox) and a His-tagged comD positive control strain (ComD+). Five S. mutant strains were also included to determine MIC and MBC (Table 1). Three oral species, S. sanguinis SK108, S. mitis SK142 and Actinomyces naeslundii WVU627 were used to develop dual-species cultures. All the strains were grown on blood agar plates or in Brain-Heart Infusion (BHI) broth at $37^{\circ} \mathrm{C}$ anaerobically, unless otherwise specified.

\begin{tabular}{|c|c|c|}
\hline Species or Strain & MIC $(\mu \mathrm{M})$ & MBC $(\mu \mathrm{M})$ \\
\hline S. mutans UA159 & 2.5 & 5.0 \\
\hline S. mutans GS5 & 2.5 & 5.0 \\
\hline S. mutans NG8 & 2.5 & 5.0 \\
\hline S. mutans BM71 & 2.5 & 5.0 \\
\hline S. mutans KK23 & 2.5 & 5.0 \\
\hline S. mutans R221 & 2.5 & 5.0 \\
\hline S. sanguinis SK108 & 10 & 20 \\
\hline S. mitis SK142 & 10 & 20 \\
\hline A. naeuslundii WVU627 & 20 & 80 \\
\hline
\end{tabular}

Table 1: Minimum Inhibitory Concentration (MIC) and Minimum Bactericidal Concentration (MBC) of HP30 against Oral Bacterial Strains

\section{Peptide synthesis}

HP30 (SGSLSTFFRLFNRGGGWGHFFKKAAHVGKLNH ${ }_{2}$ ) was chemically synthesized and C-terminally amidated to reduce its end charge and increase the stability [12]. The peptide was purified (purity $>90 \%$ ) by reversed-phase high-pressure liquid chromatography and its molecular mass was confirmed by mass spectrometry (BioBasic Inc. Ontario). The peptide was dissolved in sterile distilled water as a stock solution and further diluted to final concentrations as required in experiments.

\section{MIC and MBC tests}

Minimum inhibitory concentration (MIC) of HP30 was determined against bacterial strains by a broth micro-dilution method. Briefly, $10 \mu \mathrm{l}$ of mid-log phase cells $\left(\approx 10^{6} \mathrm{CFU} / \mathrm{ml}\right)$ was inoculated into $200 \mu \mathrm{l} /$ well of BHI containing two-fold serial dilutions of the peptide in a 96-well microtiter plate. Wells with erythromycin $(10 \mu \mathrm{g} / \mathrm{ml})$ were used as positive controls, while wells without addition of HP30 or erythromycin were used as negative controls. The cultures were incubated anaerobically at $37^{\circ} \mathrm{C}$ for 20 hours (for streptococcal strains) and for 40 hours (for Actinomyces naeslundii WVU627). The optical density of the cultures was read at $590 \mathrm{~nm}$ using a microtiter plate reader (Synergy HT, Biotek, USA). Aliquots $(20 \mu \mathrm{l})$ of samples were further taken from these cultures to determine MBC by viable cell count as described previously [12].

\section{Selective killing assay}

To determine selective killing activity of the peptide, we performed time-killing experiments against $S$. mutans strains, S. sanguinis SK108, S. mitis SK142 and A. nauslundii WVU627 in single- and dual-species cultures. Briefly, the mid-log phase cultures of all the 
strains were adjusted to the same cell density. The killing was initiated by adding aliquots of cell suspension $\left(\approx 10^{6} \mathrm{CFU} / \mathrm{ml}\right) \mathrm{into}$ the medium containing HP30 in a 96-well microtiter plate. A one-to-one ratio of two species was used in dual-species cultures. Aliquots $(20 \mu \mathrm{l})$ of samples were taken at 5 and $15 \mathrm{~min}$ for viable cell counts by spreading cells on BHI agar plates (single-species) or on blood agar plates (dual-species). The plates were incubated anaerobically at $37^{\circ} \mathrm{C}$ for 20 or 40 hours respectively before evaluation of the results. S. mutans was distinguished from other species by examining their colony morphology on blood agar plates. Percent survivals were determined by calculating the number of survivors versus total CFU/ml. The targeted killing of $S$. mutans was also examined under a fluorescence microscope (Leica AF7000) using a Live/Dead BacLight bacterial viability kit (Invitrogen).

\section{Killing activity against biofilms}

The killing activity of HP30 against $S$. mutans biofilms was examined by a microtiter plate method [12]. Biofilms were initiated by inoculating $10 \mu \mathrm{l}$ of the mid-log phase cells $\left(\approx 10^{5} \mathrm{CFU} / \mathrm{ml}\right)$ into $200 \mu \mathrm{l}$ of $2 \mathrm{X}$ diluted $\mathrm{BHI}$ broth supplemented with $10 \mathrm{mM}$ glucose in a 96-well microtiter plate. The cultures were incubated anaerobically at $37^{\circ} \mathrm{C}$ for 24 hours. Planktonic cells were removed and added carefully with the same volume of fresh medium containing HP30 for 5 and 15 min. Biofilm cells were washed off from the surfaces by pipetting using $10 \mathrm{mM}$ phosphate buffer. The cell suspensions were serially diluted and spread on agar plates to determine percent survival.

Dual-species biofilms were also developed to assay selective killing of the peptide against biofilms consisting of S. mutans UA159 co-cultured with S. sangunis SK108 or A. naeslundii WVU627. Dual-species biofilms were initiated by inoculating 1:1 ratio of two species in $2 \mathrm{X}$ diluted BHI broth plus $10 \mathrm{mM}$ glucose and $0.1 \%$ hog gastric mucin (Sigma). After 24-hour incubation, the biofilms were treated by the same ways as above. Biofilm samples were taken at 5 and $15 \mathrm{~min}$, serially diluted and spread on both BHI and blood agar plates to determine survival percentages of individual species.

\section{Detection of the ComD protein by Western blotting}

Three S. mutans strains, which were previously constructed for Western analysis of the ComD protein of S. mutans [13], were used to monitor the effects of existence of ComD protein on selective killing of HP30. These strains included a His-tagged comD control strain that expressed a wild type ComD (ComD+), a comD deletion mutant $\Delta c o m D(\mathrm{ComD}-)$ and a ComD-Ox that over-expressed a ComD protein. All the strains were grown in BHI medium with use of competence-stimulating peptide or CSP $(1 \mu \mathrm{M})$. When the cultures reached mid-log phase $\left(\mathrm{OD}_{600} \approx 0.5\right)$, aliquots of the samples were taken to prepare the crude cell lysates. The samples of the membrane fractions from individual strains were resolved on SDS-PAGE gels and transferred to polyvinylidenedifluoride (PVDF) membrane for Western blot analysis using an anti-His-tag antibody [13]. The membranes were detected with an AP (alkaline phosphatase) detection reagent (Novagen). The protein images on the membranes were examined and photographed using FluorChem SP image system (Alpha Innotech, Calif. USA).

\section{Assay for the stability of HP30 in saliva}

Unstimulated whole saliva was collected from six healthy volunteers by following a protocol of the Dalhousie Health Sciences Research Ethics Board. The saliva samples were centrifuged at 5,000 x g at $4{ }^{\circ} \mathrm{C}$ to remove food debris. The supernatants were passed through $0.2 \mu \mathrm{m}$ filters, pooled and stored at $-20{ }^{\circ} \mathrm{C}$. Killing activity of HP30 was assayed in the presence of saliva with or without $2 \mathrm{mM}$ EDTA. Viable cell counts were performed to determine percent survivals. The stability of HP30 in saliva was determined by incubating aliquots $(15 \mu \mathrm{g})$ of HP30 in $100 \mu \mathrm{l}$ of saliva with or without $2 \mathrm{mM}$ EDTA at $37^{\circ} \mathrm{C}$. Aliquots (15 $\left.\mu \mathrm{l}\right)$ of sample were taken at 0, 5, 10 and $15 \mathrm{~min}$, boiled and analyzed with 15\% SDS-PAGE gels (BioRad). A peptide sample without saliva was used as a control. The gels were stained with Coomassie blue and the peptide bands were scanned by a densitometry for calculation of $\%$ degradation compared to 0 -min sample.

\section{Statistical analysis}

All killing assays were performed in triplicate in two independent experiments. The results were analyzed by Student's $t$ test and $P$ $\leq 0.05$ was considered statistically significant.

\section{Results}

\section{HP30 shows an enhanced selectivity for targeted killing of $S$. mutans cells}

We first examined MIC and MBC of HP30 against $S$. mutans strains and several related oral species in dental biofilms. The results confirmed that HP30 displayed a potent bactericidal activity against $S$. mutans cells with a MIC of as low as $2.5 \mu \mathrm{M}$. There was little or no variation in MIC among S. mutans strains (Table 1). We then examined the killing kinetics of HP30 (MBC $5.0 \mu \mathrm{M})$ against S. mutans UA159 and other oral species, S. sanguinis SK108, S. mitis SK142 and A. naeslundii WVU627, grown in monocultures. The results showed that $82 \%$ of $S$. mutans cells were killed following exposure to HP30 $(5.0 \mu \mathrm{M})$ for 15 min (Figure 1). However, only $20 \%$ of S. sanguinis, $18 \%$ of S. mitis and 5\% of A. naeslundii were killed following the same exposure to HP30. The results clearly demonstrate that HP30 is highly effective to trigger selective killing of $S$. mutans cells, but less likely kills other oral species. 


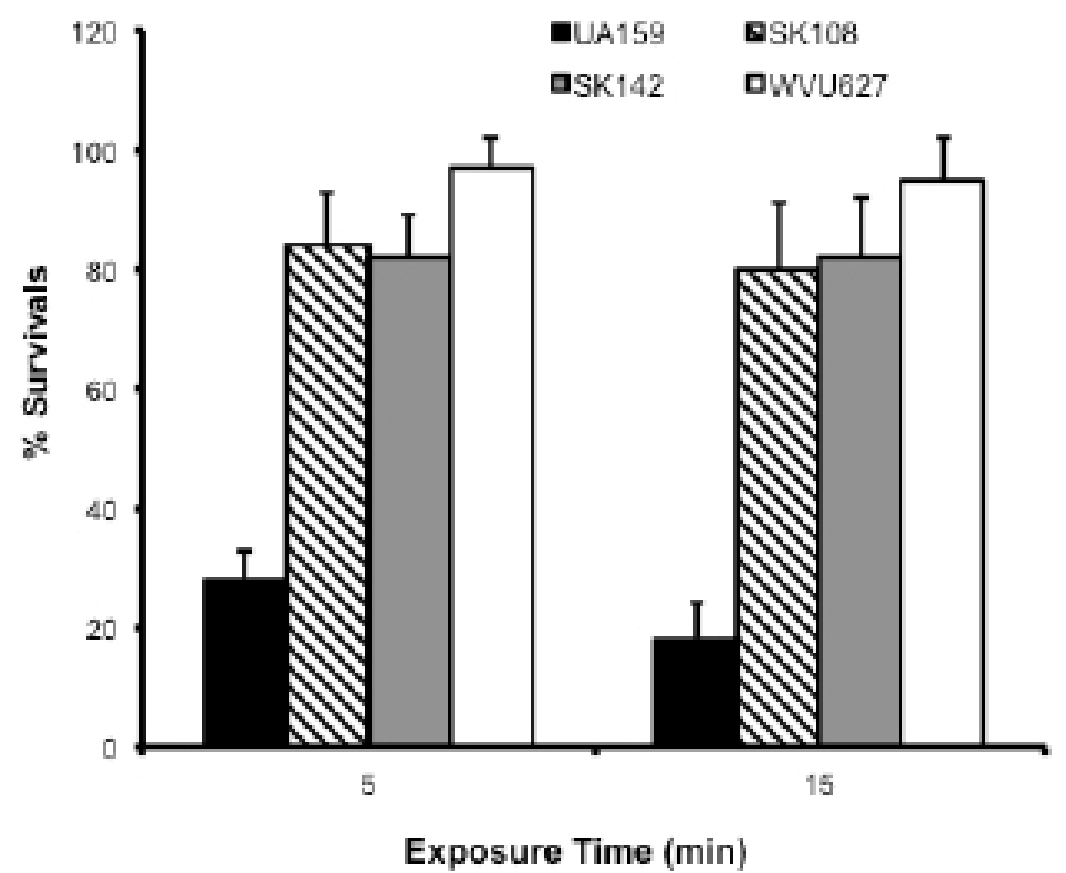

Figure 1: Killing activities of HP30 $(5.0 \mu \mathrm{M})$ against S. mutans UA159 (UA159), S. sanguinis SK108 (SK108), S. mitis (SK142) and A. naeuslundii WVU627 (WVU627) in single-species planktonic cultures. S. mutans could be distinguished from S. sanguinis and S. mitis by colony morphology and haemolysis on blood agar plates.

To further confirm the selectivity of this peptide, we examined the killing activity of HP30 (5.0 $\mu \mathrm{M})$ against $S$. mutans cells in dual-species cultures, which contained a 1:1 ratio of mid-log phase cells of S. mutans UA159 with either S. sanguinis SK108 or A.naeslundii WVU627. In the mixed culture of S. mutans and S. sanguinis, nearly $80 \%$ of S. mutans cells were killed following exposure to HP30 for $15 \mathrm{~min}$, but less than $20 \%$ of S. sanguinis cells were killed following the same exposure (Figure 2A). Similarly, HP30 killed $82 \%$ of $S$. mutans cells but killed less than $5 \%$ of $A$. naeslundii cells in dual-species culture following the same exposure (Figure 2B). The results confirm that HP30 displays a high selectivity to kill S. mutans cells in the dual-species mixed cultures.
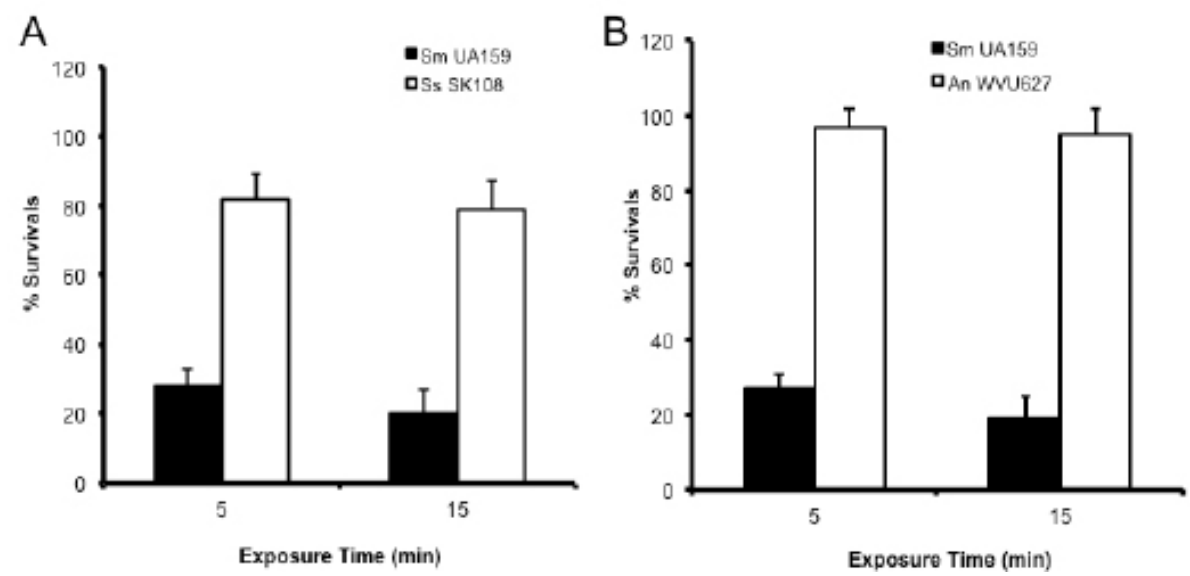

Figure 2: Selective killing activity of HP30 $(5 \mu \mathrm{M})$ against $S$. mutans in dual-species cultures consisting of $S$. mutans UA159 with either S. sanguinis SK108 (A) or with A. naeuslundii WVU627 (B).

\section{HP30 is also effective to kill S. mutans cells in the dual-species biofilms}

Next, we examined selective killing of HP30 against $S$. mutans in dual-species biofilms, which consisted of $S$. mutans UA159 with either S. sanguinis SK108 or A. naeslundii WVU627. The dual-species biofilms (one-day old) grown on 96-well microtiter plates were treated with an increasing concentration of HP30. The results showed that nearly $70 \%$ of $S$. mutans cells in the biofilms were killed following exposure to HP30 $(5.0 \mu \mathrm{M})$ for $15 \mathrm{~min}$. In contrast, only $8 \%$ of S. sanguinis or $2 \%$ of $A$. naeslundii in the biofilms were killed $(\mathrm{P}<0.01)$ following the same exposure (Figure 3). However, the targeted killing of $S$. mutans cells in the dual-species biofilms increased with increasing concentrations of HP30, suggesting that HP30 was highly effective to target $S$. mutans cells in the dual-species biofilms. To increase the efficacy of the selective killing with use of a low concentration of HP30, we combined 5 $\mu \mathrm{M}$ of HP30 with $2 \mathrm{mM}$ of EDTA to treat the biofilms. The results revealed that 15-min treatment of HP30 together with EDTA killed nearly $100 \%$ of $S$. mutans cells in the dual-species biofilms (Figure 4), while the same treatment did not increase killing of 
other species in the dual-species biofilms. Notably, $2 \mathrm{mM}$ of EDTA alone caused little effect on the viability of $S$. mutans and other species tested $(\mathrm{P}<0.001)$. The result suggests that a combination of low concentrations of HP30 and EDTA showed an additive targeted killing of $S$. mutans grown in the biofilms.
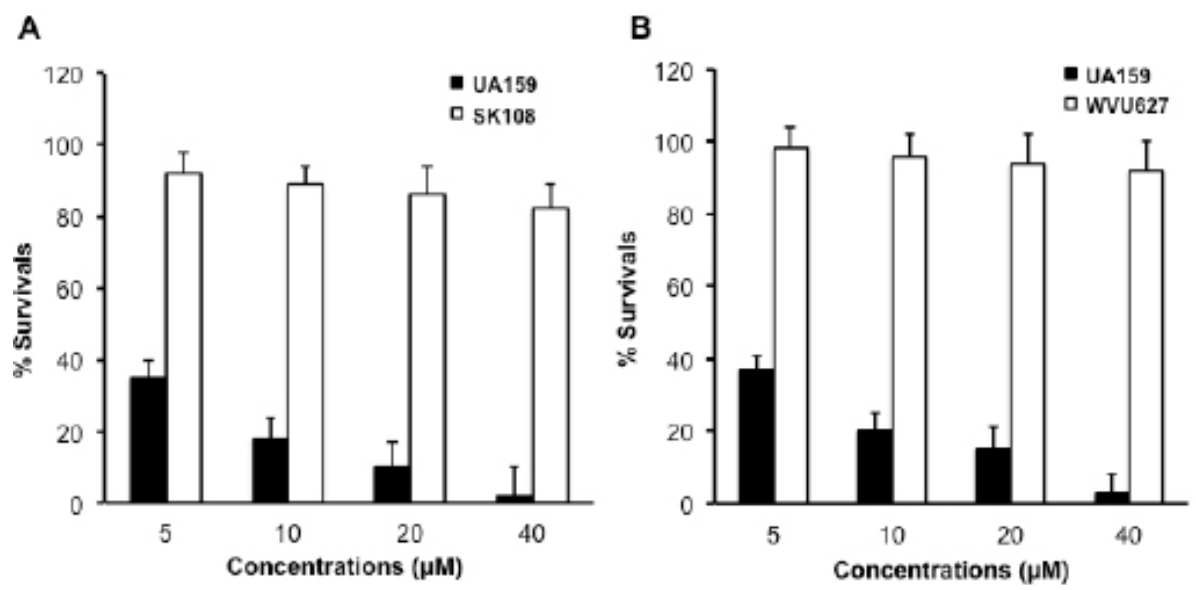

Figure 3: Selective killing activity of HP30 against $S$. mutans in dual-species biofilms consisting of $S$. mutans UA159 with either S. sanguinis SK108 (A) or with A. naeuslundii WVU627 (B).

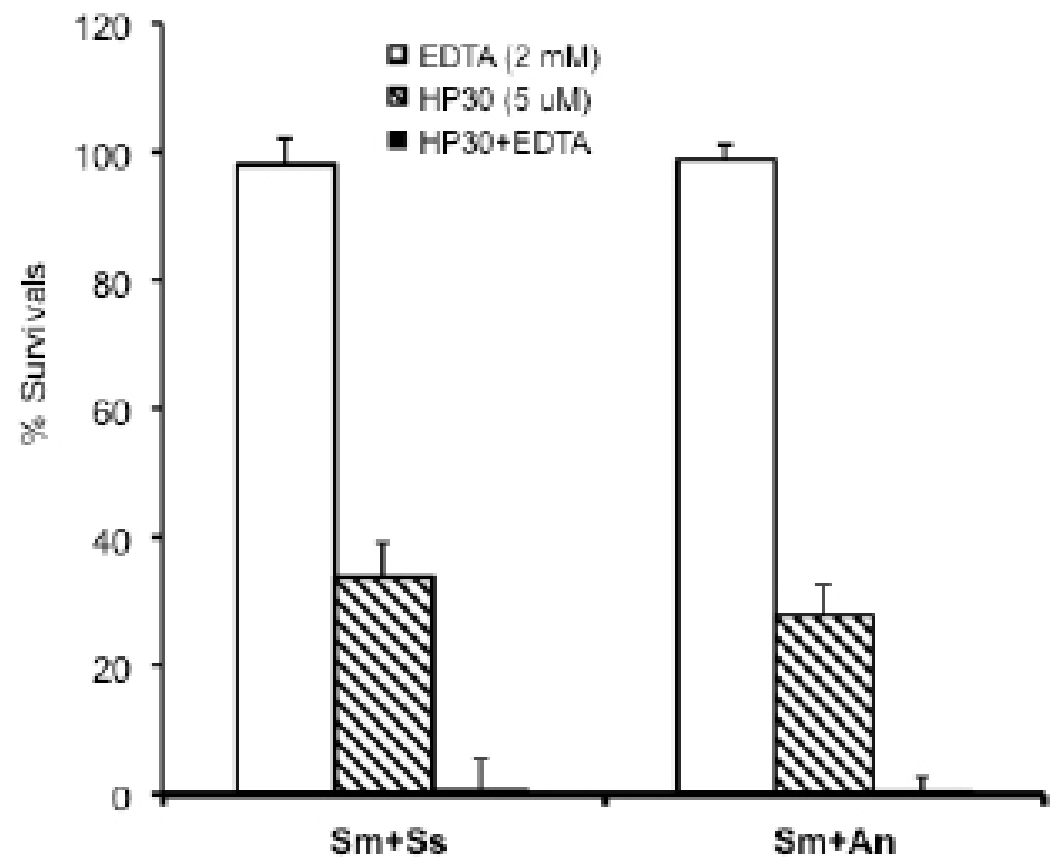

Figure 4: Killing activity of HP30 $(5 \mu \mathrm{M})$ combined with EDTA $(2 \mathrm{mM})$ against $S$. mutans cells in dual-species biofilms consisting of S. mutans UA159 (Sm) with either S. sanguinis SK108 (Ss) or with A.naeuslundii WVU627 (An). Only survival percentages of S. mutans are plotted, but the percentages of other species (Ss or An) are not included.

\section{HP30 predominantly binds to the ComD receptor protein to trigger selective killing}

Our results clearly demonstrate that HP30 displays a high selectivity for targeted killing of S. mutans cells in both mono- and dualspecies mixed cultures. However, the question whether or not HP30 needs to bind to the ComD receptor protein before it triggers selective killing remained unclear. To explore this question, we used three previously constructed $S$. mutans strains [13], including a comD deletion mutant $\Delta c o m D\left(\mathrm{ComD}^{-}\right)$, a strain that over-expresses $\mathrm{ComD}(\mathrm{ComD}-\mathrm{Ox})$ and a positive control strain $(\mathrm{ComD}+)$, to examine the effects of comD expression on selective killing of $S$. mutans. By Western blot analysis, we first confirmed the existence of a $51-\mathrm{kDa}$ protein in the membrane fractions of both ComD-Ox and positive control strains (Figure 5A), but not in the membrane fraction of $\Delta c o m D$ mutant $\left(\mathrm{ComD}^{-}\right)$. It was noted that the ComD-Ox strain showed a slightly higher level $(\approx 2.5$-fold, estimated by a densitometry) of ComD protein than the control strain $(\mathrm{ComD}+)$. The results suggest that these three strains were suitable to examine their response to targeted killing by HP30. The results from killing assays showed that compared to the parent strain UA159 (80\% of killing), nearly 95\% of the ComD-Ox cells were killed following exposure to $5.0 \mu \mathrm{M}$ of HP30 for 15 min. In contrast, only $10 \%$ of $\Delta c o m D$ mutant cells were killed $(\mathrm{P}<0.01)$ following the same exposure. The results suggest that binding to 
ComD receptor is crucial for HP30 to trigger selective killing of S. mutans. We further examined selective killing of HP30 against these strains by Live/Dead BacLight bacterial viability assay using a fluorescence microscopy (Figure 5B-a, b, c). The results confirmed that HP30 resulted in the greater killing of $S$. mutans cells that expressed or over-expressed the ComD receptor (a and b).

A)

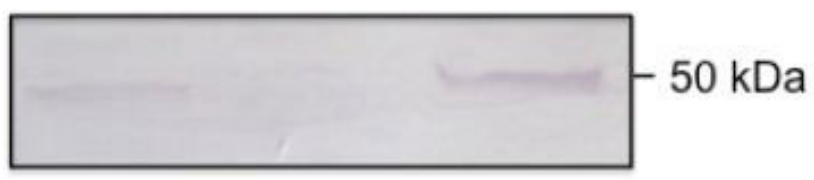

ComD $+\Delta$ ComD ComD-Ox

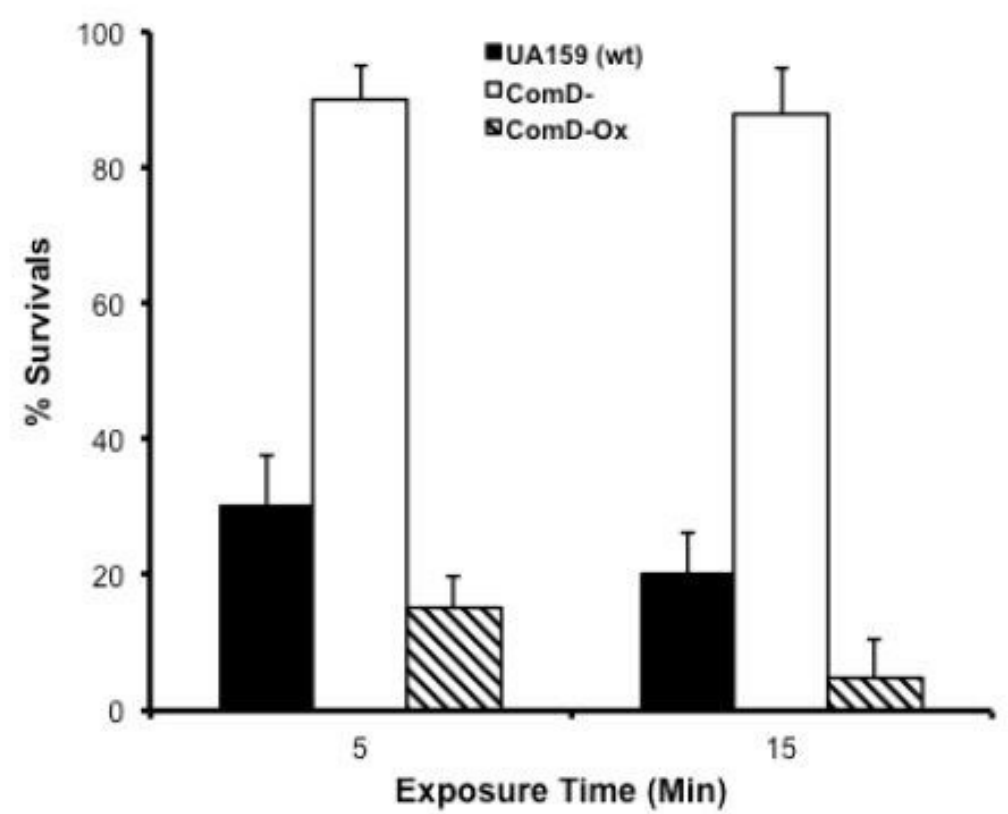

B)
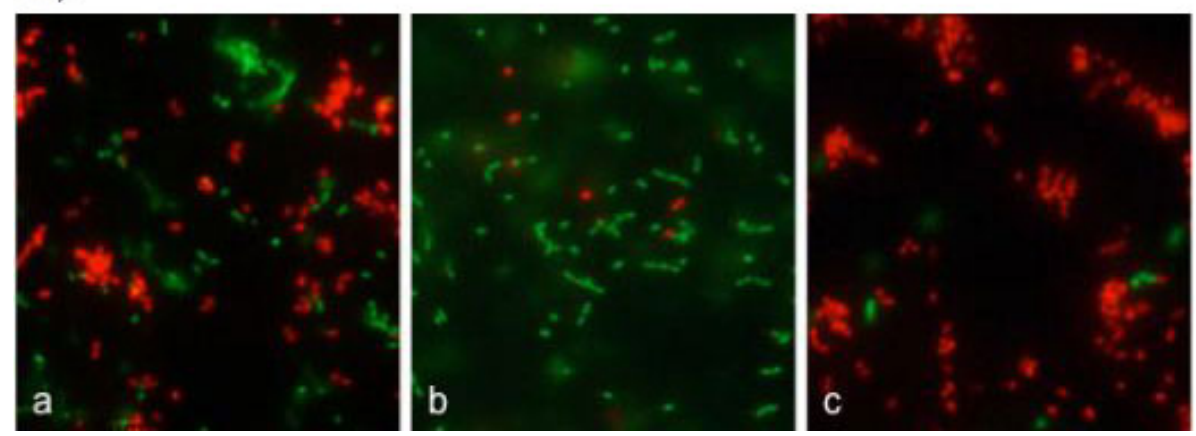

Figure 5: Killing activities of HP30 against $S$. mutans strains, including a positive control strain (ComD+), a comD deletion mutant $(\triangle c o m D)$ and a ComD overexpression strain (ComD-Ox). A-up. Western blotting confirmation of the His-tagged ComD protein in strains ComD+, $\triangle$ ComD and ComD-Ox. A-down. Killing activities of HP30 against S. mutans UA159 (wt), $\triangle$ comD (ComD-) and ComD-Ox. B. Fluorescence microscopy of targeted killing of S. mutans biofilm cells following exposure to HP30 $(5.0 \mu \mathrm{M})$ for 15 minutes. The cells are labelled with Live/Dead BacLight bacterial viability dye (viable cells are green and dead cells are red). a. S. mutans UA159 (wt), b. $\Delta$ comD (ComD-) strain and c. ComD-Ox strain.

\section{The stability of HP30 in the presence of human saliva}

We then examined the killing activity of HP30 against $S$. mutans cells in the presence of human saliva. The results showed that in the presence of saliva only $50 \%$ of $S$. mutans cells were killed following exposure to HP30 for 15 min (Figure 6A). Compared to THYE medium only, this indicated a significant decrease $(\mathrm{P}<0.05)$ in the killing activity, suggesting that the presence of saliva decreases the killing activity of HP30. However, adding $2 \mathrm{mM}$ of EDTA into the saliva did not only prevent saliva-induced decrease of the killing activity but also enhanced the killing activity of $\mathrm{HP} 30(\mathrm{P}<0.01)$. The results suggest that a low concentration of EDTA appears to stabilize and enhance the killing activity of HP30 in the presence of saliva. To further confirm this observation, we examined the stability of HP30 in the presence of saliva by incubating an aliquot of the peptide $(15 \mu \mathrm{g})$ in saliva at $37^{\circ} \mathrm{C}$ followed by SDS-PAGE analysis of the peptide profile. The results showed that exposure of the peptide to saliva without EDTA resulted in progressive degradation during 15-min incubation (Figure 6B), lanes 3-6). However, adding 2.0 mM EDTA into the saliva 
significantly reduced the degradation of HP30 (lane 7-10), which was consistent with the results of the killing activity observed.

A)
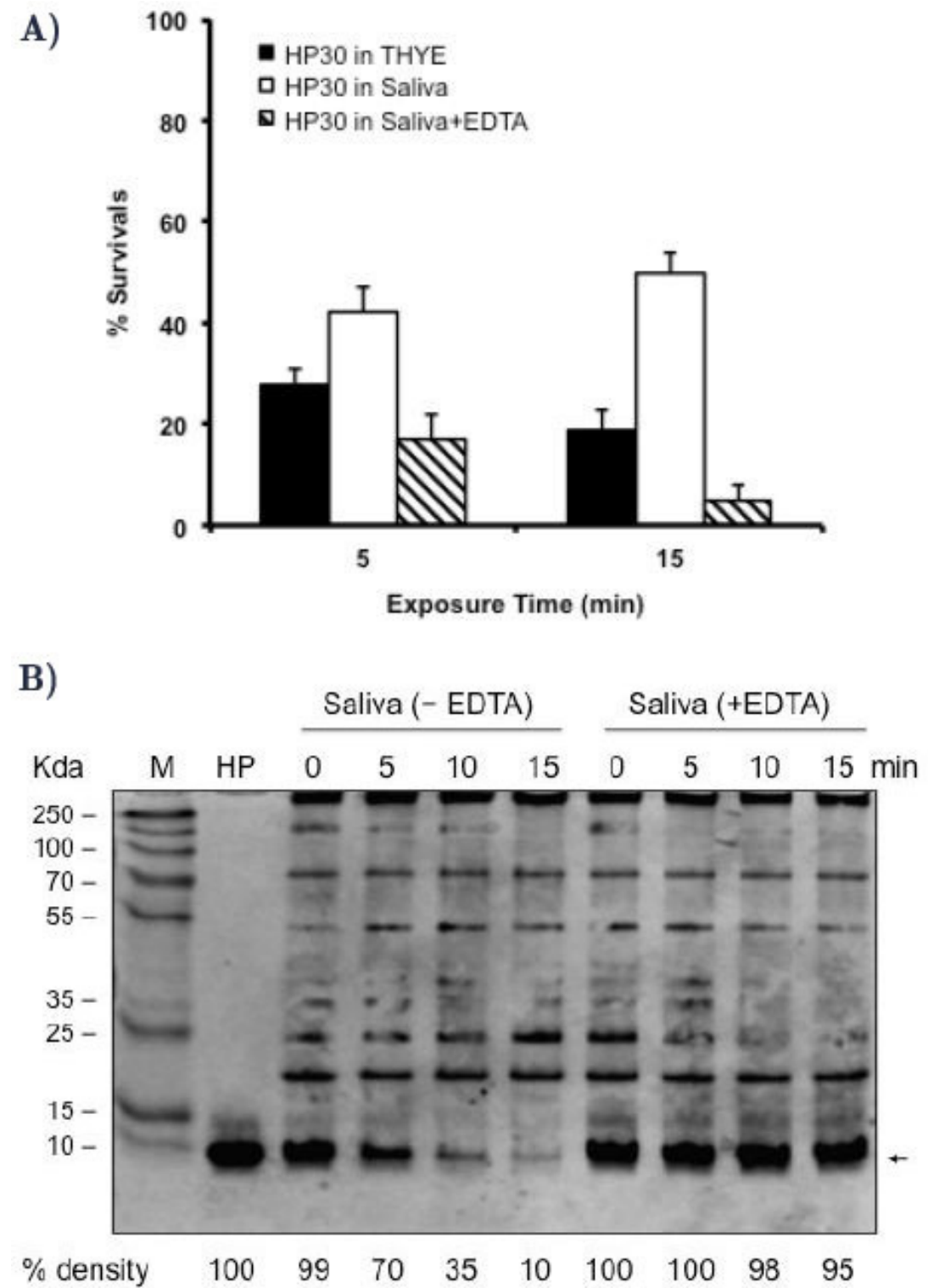

Figure 6: The killing activity and stability of HP30 $(5 \mu \mathrm{M})$ in the presence of human saliva. A. The survival percentages of $S$. mutans cells in saliva exposed to HP30 with or without addition of EDTA ( $2 \mathrm{mM})$. B. SDS-PAGE analysis of the peptide profiles in the presence of saliva with or without addition of $2 \mathrm{mM}$ EDTA. The peptide bands were scanned and quantitated by a densitometry to calculate $\%$ density. Lane 1: a low molecular weight marker; Lane 2 : HP30 only ( $\approx 4.5$ $\mathrm{KDa}$ ) as a blank control; Lanes 3-6: HP30 exposed to saliva without 2 mM EDTA (- EDTA) for 0, 5, 10 and 15 min; Lanes 7-10: HP30 exposed to saliva with EDTA (+ EDTA) for 0, 5, 10 and $15 \mathrm{~min}$. Arrow indicates HP30.

\section{Discussion}

In this study, we investigated selective killing activity of a new PG-AMP, HP30, against a leading cariogenic pathogen, $S$. mutans, and other species, in both mono- and dual-species cultures. Our goal was to identify and validate a target-specific antimicrobial agent that selectively kills $S$. mutans cells with minimal disruption of other species in a biofilm community. The results demonstrate that HP30 shows an improved selectivity to target $S$. mutans cells for killing in both planktonic and biofilm cultures, although its killing activity in monocultures is nearly the same as a previously reported PG-AMP, IMB-2 [12]. The results from this study suggest that the improved selectivity in targeted killing likely results from an improved binding of HP30 to the ComD receptor protein of $S$. mutans. This suggestion is strongly supported by several lines of evidence. First, the enhanced killing activity of HP30 against $S$. mutans is clearly observed in both mono-and dual-species cultures, suggesting that the killing activity is species-specific. Second, a deletion of comD that encodes the CSP receptor results in significant reduction (nearly $80 \%$ ) in the killing activity of S. mutans. In contrast, the over-expression of the comD significantly increases its killing activity (up to 90\%), suggesting that the existence of an intact ComD receptor protein is the key requirement for the selective killing of $S$. mutans. This also suggests that HP30 predominantly binds to the ComD receptor protein before it triggers the selective killing. Third, HP30 was designed in such a way that its target domain contains five extra residues, SGSLS, at its N-terminal arm, which makes the N-terminus of 
HP30 identical to that of CSP (Table 2). Our previous study by structure-activity analysis of $S$. mutans CSP showed that the core hydrophobic $a$-helix of CSP along with its N-terminus was essential for peptide binding to the ComD receptor [12]. Thus, adding the $\mathrm{N}$-terminal five original residues to the fusion peptide would increase the binding of the fusion peptide to the ComD receptor. It is therefore reasonable to assume that HP30 may bind more effectively to the ComD receptor than IMB-2 or IMB2 (H/S14), because it retains the intact $\mathrm{N}$-terminus and core hydrophobic a-helix that promote the binding to the ComD receptor. We also speculate that HP30 triggers the killing of $S$. mutans cells immediately after it binds to the ComD receptor protein. This speculation is based on the fact that HP30 shows a highly selective killing activity against $S$. mutans cells, even in the mixed-species biofilms.

\begin{tabular}{|c|c|c|}
\hline Name & $\begin{array}{c}\text { Fusion Peptide (targeting domain - linker - killing } \\
\text { domain) }\end{array}$ & MIC $(\boldsymbol{\mu M})$ \\
\hline CSP-18* & SGSLSTFFRLFNRSFTQA & NA \\
\hline CSP-21 ${ }^{\star}$ & SGSLSTFFRLFNRSFTQAñLGK & NA \\
\hline IMB-2 & TFFRLFNR -GG- GWGSFFKKAAHVGKL•NH2 & 2.8 \\
\hline IMB2-(H/S14) & TFFRLFNR -GG- GWGHFFKKAAHVGKL•NH2 & 2.8 \\
\hline HP30 & SGSLSTFFRLFNR -GG- GWGHFFKKAAHVGKL•NH2 & 2.5 \\
\hline C16G2 & TFFRLFNRSFTQAñLGK -GGG- KNLRHRKGIHIIKKY & 5.2 \\
\hline
\end{tabular}

*: CSP-18: competence-stimulating peptide from S. mutans after C-terminal cleavage (ñ) by SepM; CSP-21: CSP before the C-terminal cleavage (ñ); Underline represents the core hydrophobic $\alpha$-helical structure (minimal targeting sequence of CSP); H/S14 (H): His-to-Ser14 substitution. $\mathrm{NH}_{2}$ : the C-terminal amidation (to increases the stability). MIC: minimum inhibitory concentration. NA: not applicable.

Table 2: The Peptide Sequences from Known PG-AMPs Specific to S. mutans

Despite the high efficacy in targeted killing of $S$. mutans, the exact mechanism how HP30 triggers the killing of $S$. mutans remains unclear. The evidence from this study suggests that, as the originally designed, HP30 likely binds to the ComD receptor by its targeting domain (the $N$-terminal arm) before it rapidly triggers the killing by its killing domain (the $C$-terminal arm). However, Kaplan et al. report a similar PG-AMP, C16G2, which contains a portion (the core hydrophobic a-helix and the $C$-terminus) of $S$. mutans CSP (Table 2) [14]. These researchers have found that C16G2 also kills S. mutans cells in a species-specific manner, but the killing by C16G2 is independent on the ComD receptor. Their work suggests that C16G2 may involve the membrane partition steps that enable C16G2 to bind and retain on the S. mutans surface. Such retention of C16G2 on the cell surface then results in loss of membrane potential $(\Delta \Psi)$ of $S$. mutans cells, triggering the cell death at a level of potency similar to a peptide antibiotic melittin $\mathrm{B}$ [14]. This suggests that the ComD receptor, which is supposed to be the binding site for the peptide, plays little or no role in targeting of C16G2 to the surface of $S$. mutans cells. This divergence was not very clear until the recent discovery that $S$. mutans can produce an extracellular protease SepM that is required for the cleavage of $C$-terminal three residues, LGK, of CSP-21 to generate a functional CSP-18 [14] (Table 2). Since C16G2 contains an intact C-terminus of CSP-21, including LGK, it suggests that the $C$-terminal killing domain of C16G2 could be cleaved off from the cleavage site by SepM, resulting in release of two independent peptide moieties, the targeting domain and killing domain [15]. In contract, the targeting domain of HP30 or IMB-2 does not have the $C$-terminal three residues, LGK, this implies that the $C$-terminal killing domain of HP30 and IMB-2 would not be subject to the cleavage by SepM. Therefore, the discovery of protease SepM may explain the divergence in the action mechanisms of these known fusion peptides, C16G2 and HP30. Thus, the action mechanism of C16G2 observed by Kaplan et al. can be interpreted as the action mode by the killing domain alone, which is truly consistent with their observation [14]. Nevertheless, this does not exclude the possibility that peptides HP30 and IMB-2 may also involve a low level of non-specific binding to the surface of $S$. mutans, since it kills $5-10 \%$ of the ComD deletion mutant cells.

It is well known that biofilms in nature inherently resist treatment of antimicrobial agents by a number of mechanisms, including drug diffusion limitation in biofilms [16]. This often requires increasing concentrations of the antimicrobial agents to achieve expected results, but the higher doses of an antimicrobial also increase negative or side effects of the drug [17]. To circumvent this problem, some strategies have been proposed to improve killing activity of an antimicrobial agent to treat biofilm infections without use of too much drugs. Among these strategies, EDTA (ethylenediaminetetraacetic acid), a well-known chelating agent, is frequently reported to show anti-biofilm activity due to its chelation of divalent cations required for stabilizing biofilm matrix $[18,19]$. EDTA is found to increase sensitivity of bacteria to killing by antibiotics, showing synergic effect on biofilms. For example, EDTA combined with minocycline is effective against biofilms formed by Staphylococcus epidermidis, S. aureus and Pseudomonas aeruginosa [20]. At a higher concentration, EDTA can directly result in bacterial viability loss [19]. In our study, we also confirm that a low concentration $(2 \mathrm{mM})$ of EDTA combined with HP30 $(5 \mu \mathrm{M})$ does not only increase the stability of the peptide in the presence of saliva but also enhances selective killing of $S$. mutans cells grown in biofilms. Our work highly recommends such an application by combining a low concentration of EDTA with a selected antimicrobial agent, such as HP30, to deal with a biofilm disease caused by a pathogen living along with the resident microflora.

In conclusion, we have evaluated a novel PG-AMP HP30 that shows an improved selectivity to kills S. mutans. The evidence suggests that the improved selectivity in the targeted killing results from an improved binding of HP30 to the ComD receptor of $S$. 
mutans. Our work also confirms that a combination of a low concentration of EDTA with HP30 significantly enhances the killing activity of HP30 against $S$. mutans in biofilms. Such a combination makes HP30 more effectively target $S$. mutans and extend its killing activity in the presence of saliva. Because of its improved selectivity and effectiveness, HP30 shows good promise for future development as a target-specific antimicrobial agent against $S$. mutans in dental biofilms.

\section{Acknowledgment}

This work was supported by the Canadian Institutes for Health Research (CIHR) Operating Grant MOP-115007 and by the Natural Sciences and Engineering Research Council of Canada (NSERC) Discovery Grant RGPIN 311682-07. C.C. and K.C. were the recipients of the Faculty Summer Research Studentship Award. H.S. was the recipient of a NSERC Summer Research Studentship Award.

\section{Conflict of Interest}

The authors declare that they have no competing financial interest.

\section{References}

1. Ajdic D, McShan WM, McLaughlin RE, Savić G, Chang J, et al. (2002) Genome sequence of Streptococcus mutans UA159, a cariogenic dental pathogen. Proc NatlAcad Sci USA 99: 14434-39.

2. Marsh PD (1994) Microbial ecology of dental plaque and its significance in heath and disease. Adv Dent Res 82: 263-71.

3. Bowen WH (2002) Do we need to be concerned about dental caries in the coming millennium? Crit Rev Oral Biol Med 13: 126-31.

4. Mitchell TJ (2003) The pathogenesis of streptococcal infections: from tooth decay to meningitis. Nat Rev Microbiol 1: 219-30.

5. Brogden NK, Brogden KA (2011) Will new generations of modified antimicrobial peptides improve their potential as pharmaceuticals? Int J Antimicb Agents 38: $217-25$.

6. Qiu XQ, Wang H, Lu XF, Zhang J, Li SF, et al. (2003) An engineered multidomain bactericidal peptide as a model for targeted antibiotics against specific bacteria. Nat Biotechnol 21: 1480-5.

7. Qiu XQ, Zhang J, Wang, Wu HGY (2005) A novel engineered peptide, a narrow- spectrum antibiotic, is effective against vancomycin-resistant Enterococcus faecalis. Antimicrob Agents Chemother 49: 1184-9.

8. Franzman MR, Burnell KK, Dehkordi-Vakil FH, Guthmiller JM, Dawson DV, et al. (2009) Targeted antimicrobial activity of a specific IgG-SMAP28 conjugate against Porphyromonas gingivalis in a mixed culture. Int J Antimicrob Agents 33: 14-20.

9. Li YH, Tian XL (2012) Quorum sensing and bacterial social interactions in biofilms. Sensors 12: 2519-38.

10. Syvitski RT, Tian XL, Sampara K, Salman A, Lee SF, et al. (2007) Structure-activity analysis of quorum-sensing signaling peptides from Streptococcus mutans. J Bacteriol 189: 1441-50.

11. Eckert R, He J, Yarbrough DK, Qi F, Anderson MH, et al. (2006) Targeted killing of Streptococcus mutans by a pheromone-guided "smart" antimicrobial peptide. Antimicrob Agents Chemother 50: 3651-7.

12. Mai J, Tian XL, Gallant JW, Merkley N, Biswas Z, et al. (2011) A novel target- specific, salt-resistant antimicrobial peptide against the cariogenic pathogen Streptococcus mutans. Antimicrob Agents Chemother 55: 5205-13.

13. Dong GF, Tian TL, Cyr K, Liu TL, Lin W, et al. (2016) Membrane topology and structural insights into the peptide pheromone receptor ComD, a quorum sensing histidine protein kinase of Streptococcus mutans. Scientific Report 6: 26502.

14. Kaplan CW, Sim JH, Shah KR, Kaplan AK, Shi WJ, et al. (2011) Selective membrane disruption: mode of action of C16G2, a specifically targeted antimicrobial peptide. Antimicrobi Agents Chemother 55: 3446-52.

15. Hossain MS, Biswas I (2012) An extracellular protease, SepM, generates functional competence-stimulating peptide in Streptococcus mutans UA159. J Bacteriol 194: 5886-96.

16. Marsh PD, Bradshaw DJ (1997) Physiological approaches to the control of oral biofilms. Adv Dent Res 11: 176-85.

17. Hogan D, Kolter R (2002) Why are bacteria refractory to antimicrobials? Curr Opin Microbiol 5: 472-7.

18. Chang Y, Gu W, McLandsborough L (2012) Low concentration of ethylenediaminetetraacetic acid (DETA) affects biodilm formation of Listeria monocytogenes by inhibiting its initial adherence. Food Microbiol 29: 10-7.

19. Banin E, Brady KM, Greenberg EP (2006) Chelator-induced dispersal and killing of Pseudomonas aeruginosa cells in a biofilm. Appl Environ Microbiol 72: 2064-9.

20. Lambert RJW, Hanlon GQ, Denye SP (2004) The Synergistic effect of EDTA/Antimicrobial combinations on Pseudomonas aeruginosa. J Appl Microbiol 96: 244-53. 


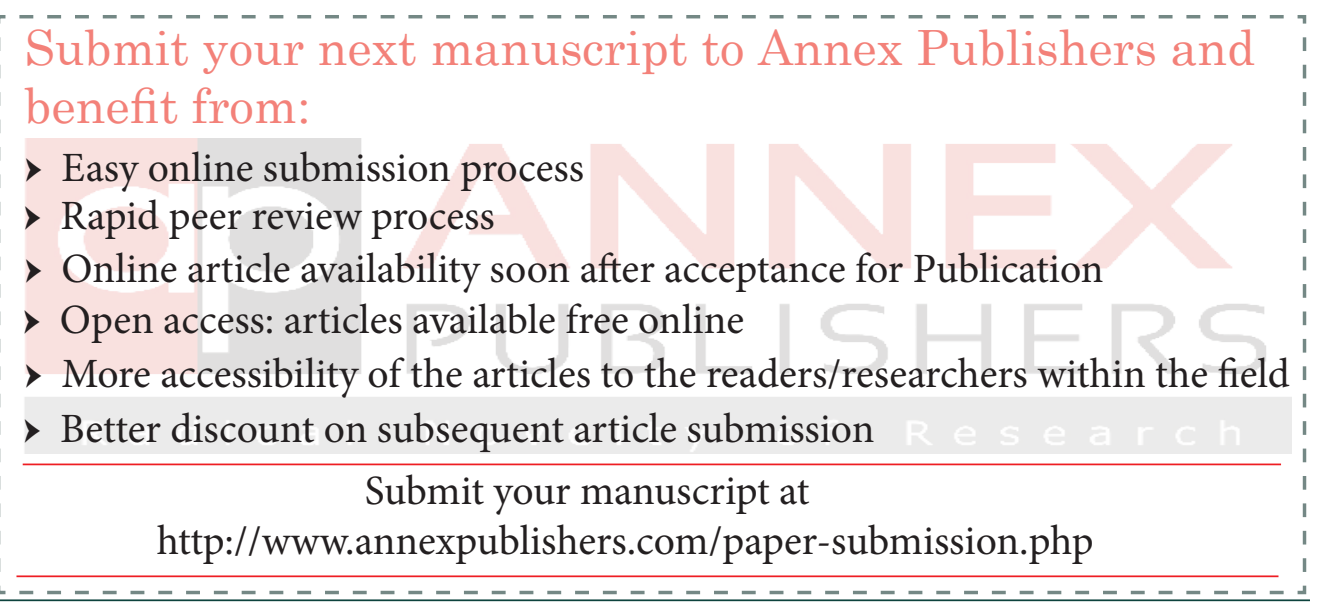

